\title{
Effect of Upper Thoracic Mobilization on Chronic Mechanical Neck Pain
}

\author{
HOSSAM ALDEN AL-BASSIOUNY, M.Sc.*; SALWA SHENDY, Ph.D.** and HAMED EL-KHOZAMY, Ph.D.** \\ The Department of Physical Therapy for Musculoskeletal Disorder, Al-Rahmania Hospital*and Faculty of Physical Therapy, \\ Cairo University**, Egypt
}

\begin{abstract}
Background: Recently, attention has been given to use the manual therapy for thoracic spine to treat Mechanical Neck Pain (MNP).

The Aim of Study: To investigate the effect of upper thoracic mobilization on Cervical Range of Motion (CROM), resting pain level and functional abilities of the neck in patients with chronic mechanical neck pain.

Subjects and Method: Thirty patients with chronic mechanical neck pain participated in this study. Subjects were divided into two groups, fifteen in each group. The first group was the treatment group (Group A) who received upper thoracic mobilization and traditional physical therapy program; and the second group was the control group (Group B) who received the traditional physical therapy program only. Before and after the treatment, the CROM was measured by baseline cervical inclinometer, the rest pain level was measured by a Visual Analog Scale (VAS) and neck disability was measured by Neck Disability Index (NDI). Patients in treatment group were treated with upper thoracic mobilization, infra-red, transcutaneous electrical nerve stimulation and cervical muscle stretching exercises. On the other hand, patients in control group were treated the same like treatment group without upper thoracic mobilization.
\end{abstract}

Results: There is a statistical significant difference between both groups. There is a positive effect of upper thoracic mobilization on CROM and neck function when comparing with routine physical therapy, there was no a statistical significant effect of upper thoracic mobilization on resting pain level when compared with routine physical therapy.

Conclusion: There is a positive effect of upper thoracic mobilization on all CROM and neck function, although there was no a significant effect on resting pain level.

Key Words: Mechanical neck pain - Upper thoracic spineMobilization.

Correspondence to: Dr. Hossam Alden Al-Bassiouny, The Department of Physical Therapy for Musculoskeletal Disorder, Al-Rahmania Hospital

\section{Introduction}

NECK pain is a common occurrence within the general population, estimated to affect $10 \%$ of the adult population at any given time [1]. It is thought that approximately $50-70 \%$ of individuals will experience neck pain at least once during their lifetime and up to $60 \%$ of patients continue to report chronic pain 5 years after onset of symptoms [2]. The economic burden associated with the management of patients with MNP is high in annual workers compensation costs [3].

Mechanical neck pain is pain and/or stiffness in the neck or shoulder girdle region which was reproducible with neck movements [4]. The source of MNP is related to various pain-sensitive structures, including the facet joints, ligaments, muscles, uncovertebral joints, intervertebral discs, or neural tissues around the cervical spine [5].

Treatment of MNP includes medication and physical therapy such as massage, manipulation, mobilization [6] and cervical traction [7]. There are also other treatment options: For example, heat application, acupuncture, and electro-physical modalities [8].

The upper thoracic spine (T1-T6) provides range of approximately $25 \%$ of the cervical flexion/ extension, $10 \%$ of the cervical rotation, and $14 \%$ of the cervical lateral flexion [9]. The hypo mobility of the thoracic vertebra may be a fundamental cause of cervical disorder in terms of the biomechanical correlation between the cervical spine and thoracic vertebra [10].

Previous studies documented the good effect of thoracic manipulation on CROM, resting pain 
level and neck function in MNP [11,12]; however, previous studies have not provided evidence on the thoracic mobilization to have the same effect in patients with MNP.

Recent studies have shown that performing thoracic spine mobilization on MNP can result in immediate and short term improvements in CROM, resting pain level and neck function $[13,14]$. There is insufficient evidence on the effectiveness of upper thoracic mobilization for individuals with MNP especially the most studies demonstrated the immediate and the short term effect for upper thoracic mobilization. The purpose of this study was to investigate the effect of upper thoracic mobilization on CROM, resting neck pain and functional abilities of the neck in patients with chronic MNP after 12 follow-up session.

\section{Patients and Methods}

\section{Patients:}

Thirty subjects referred by orthopedic specialist as MNP. Randomly assigned into equal group, Group (A) is the treatment group who received upper thoracic mobilization, infra-red, transcutaneous electrical nerve stimulation and cervical muscles stretching exercises, Group (B) is the control group who received the same treatment like Group (A) without upper thoracic mobilization. The inclusion criteria were: Their ages ranged from 20 to 40 years, they have a chief complaint of reproducible, MNP with a primary location between the supranuchal line and the first thoracic spinous process, non-athletic patients, both genders, the patient complains from 3 months to 3 years. Exclusion criteria were: A history of any of the following condition: inflammatory or osteometabolic diseases or any congenital disorders and rheumatic disorders, a history of neurological diseases, a history of vertebral fractures and surgical spinal fixation, and for female pregnancy. The study was performed at outpatient clinic of Al-Rahmania Hospital, Al-Beheira, Egypt; from the $1{ }^{\text {st }}$ February 2017 to $31{ }^{\text {st }}$ November 2017.

\section{Procedures:}

\section{A- Assessment procedures:}

Prior to randomization, all patients underwent a standardized history and physical examination. The history included demographic variables (age, sex, the mode of onset, duration of symptoms, nature and location of symptoms, and mechanism of injury), as well as questions regarding aggravating and relieving factors and any prior history of neck pain. CROM, pain level and neck function were measured before and after treatment.

Baseline inclinometer was used for assessing CROM. The data is taken 3 times and calculate the mean. Prior testing has shown the CROM inclinometer to be highly reliable with intra-rater reliability ranging from 0.91 to 0.95 [15]. Active neck flexion and extension, the patient was in sitting position with good posture and arms relaxed at the sides. The therapist stood to the side and slightly behind the patient to clearly observe cervical motion. The patient was instructed to slowly nod the head and bend the cervical spine forward. Flexion was measured with an inclinometer placed in a midsagittal position on the top of the head. Extension CROM was the same procedure in flexion but the patient instructed to slowly look up and bend the cervical spine backward as far as he or she can move comfortably.

Active neck right and left side bending, the patient was in sitting position with erect posture and arms relaxed at the sides. The therapist stands directly behind the patient. The patient is instructed to side bend the cervical spine by slowly dropping the head and neck toward the right shoulder then the left shoulder. Motion can be measured with an inclinometer placed in the frontal plane on top of the head.

Active neck right and left rotation, the patient was supine with the head resting on a small-to medium-sized pillow to support the head and neck in a neutral position with the face parallel with the plane of the treatment table. The therapist stands at the head of the table. The patient was instructed to rotate the cervical spine by slowly turning the head and neck to look over the right shoulder then to the left shoulder. A gravity inclinometer can be positioned on the forehead and used to measure the motion.

The pain at rest was measured using the VAS. The VAS was a $10-\mathrm{cm}$ line, oriented horizontally, with one end representing ( 0$)$ and the other end representing (10). The patient was asked to mark a place on the line corresponding to the current pain intensity.

All patients received a verbal description of how to fill in NDI and then were instructed to choose only one answer that most closely suited their condition at the present time. The score of each item varied between 0 (no pain and no functional limitation) and 5 (worst pain and maximal 
limitation) resulting in a total score of 0 (no disability) to 50 (totally disabled) (Appendix).

\section{B- Treatment procedures:}

Both groups were received a traditional program for 4 weeks, 3 sessions per week. All of patients received the same physiotherapy program from the same physiotherapist. Superficial thermotherapy was applied by an infrared lamp ( 250 watts), located $50 \mathrm{~cm}$ from the patient's neck for 15 minutes. Electrotherapy was provided in the form of TENS with a frequency of $100 \mathrm{~Hz}$ and $250 \mathrm{microsecond} \mathrm{pulses}$ for 20 minutes using two $4 \times 6 \mathrm{~cm}$ electrodes placed bilaterally at the spinous process of $\mathrm{C} 7$ vertebra. Stretching exercises for Upper Trapezius, Levator Scapulae, Sternocleidomastoid and Scalenes muscles, each stretching exercise maintain 30 second and repeated 5 times for each side.

The treatment group received upper thoracic mobilization according to Maitland (2005) [5] additional to the previous program. The transverse mobilization, the patient lied prone with arms to the side and head in a 'forehead rest position'. Mobilization was applied to spinal levels T1 through T6. The therapist stood at the level of the vertebra to be mobilized on one side of the subject Fig. (1). The pad of the therapist's non dominant thumb was placed in contact with the lateral aspect of the spinous process of $\mathrm{T} 1$, whereas the dominant thumb was placed on the dorsal side of the other thumb. The depth and frequency of the forces can be modified to perform graded oscillations III to IV. The transverse mobilization was performed for 30 seconds, and then sequentially applied to the next caudal level through T6. The same pattern of application was used on the participant's contralateral side. The entire procedure was repeated once again for a total of 6 minutes.

The posteroanterior mobilization was performed for 30 second at the $\mathrm{T} 1$ spinous process as described by Maitland et al., (2005). Subject was positioned in the prone position. The caudal hand, the second and third digits are used as "dummy" fingers, with the pads of the second and third fingers placed on the transverse processes of the targeted vertebra. Cranial hand, the palmar aspect of the fifth metacarpal is placed over the dummy fingers. The therapist takes up the slack and induces posteroanterior force at the specified segment. The depth and frequency of the forces can be modified to perform graded oscillations III to IV. This process will continue sequentially in a caudal direction to T6, for an overall intervention time of approximately 3 minutes Fig. (2).

\section{Statistical analysis:}

Descriptive statistics and $t$-test were conducted for comparison of subject characteristics between both groups. $t$-test was conducted to compare mean values of VAS, NDI and cervical ROM between both groups; and paired $t$-test was conducted to compare between pre and post treatment mean values of the measured variables in each group. The level of significance for all statistical tests was set at $p<0.05$. All statistical tests were performed through the Statistical Package for Social Sciences (SPSS) Version 19 for windows (IBM SPSS, Chicago, IL, USA).

\section{Results}

\section{Subject characteristics:}

Table (1) showed the mean \pm SD age, weight, height and BMI of Group A and B. There was no significant difference between both groups in the subject characteristics $(p<0.05)$.

\section{Within group comparison:}

There was a significant decrease in VAS and NDI post-treatment in Group A compared with that pre treatment ( $p=0.0001)$ with the percent of decrease in VAS and NDI were 67.9 and $59.61 \%$ respectively. There was a significant increase in cervical ROM post-treatment compared with that pre-treatment $(p=0.0001)$. The percent of increase in flexion, extension, right rotation, left rotation, right side bend and left side bend were 40, 70.96, 96.27, 98, 89.91, and 89.17 respectively (Table 2 ).

Regarding Group B, there was a significant decrease in VAS and NDI post-treatment in compared with that pre-treatment $(p=0.0001)$ with the percent of decrease in VAS and NDI were 63.17 and $48.49 \%$ respectively. There was a significant increase in cervical ROM post-treatment compared with that pre treatment $(p=0.0001)$. The percent of increase in flexion, extension, right rotation, left rotation, right side bend and left side bend were $17.45,42.82,47.6,56.85,58.07$, and 59.08 respectively (Table 2).

\section{Comparison between groups:}

There was no significant difference between both groups in all variables pre-treatment $(p>0.05)$. Comparison between groups post-treatment revealed a non significant difference in VAS $(p=0.5)$; while there was a significant decrease in NDI of Group A compared with that of Group B ( $p=0.007)$. Also, there was a significant increase in cervical ROM of Group A compared with that of Group B post-treatment $(p>0.01)$ (Table 3$)$. 


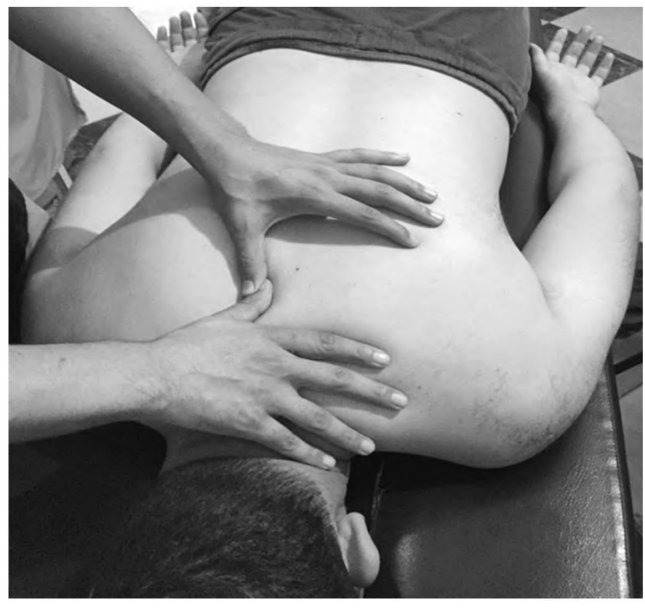

Fig. (1): The transverse mobilization of upper thoracic spine.

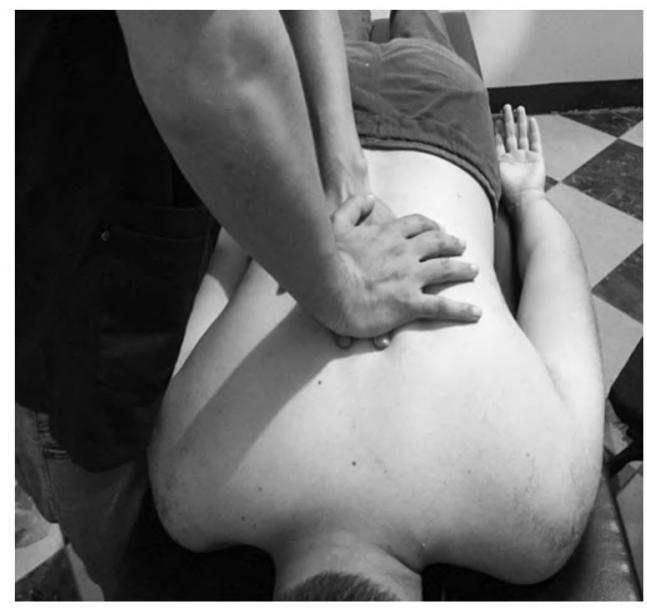

Fig. (2): Postero-anterior mobilization of upper thoracic spine.

Table (1): Comparison of subject characteristics between Group A and B.

\begin{tabular}{|c|c|c|c|c|c|}
\hline & \multicolumn{2}{|c|}{$\mathrm{X} \pm \mathrm{SD}$} & \multirow{2}{*}{ MD } & \multirow{2}{*}{$\begin{array}{c}t- \\
\text { value }\end{array}$} & \multirow{2}{*}{$\begin{array}{c}p- \\
\text { value }\end{array}$} \\
\hline & Group A & Group B & & & \\
\hline Age (years) & $28.93 \pm 4.96$ & $28.53 \pm 3.83$ & 0.4 & 0.24 & $0.8^{*}$ \\
\hline Weight (kg) & $73.2 \pm 7.01$ & $74.26 \pm 8.39$ & -1.06 & -0.37 & $0.7^{*}$ \\
\hline Height (cm) & $170.46 \pm 7.16$ & $171.4 \pm 5.51$ & -0.94 & -0.4 & $0.69 *$ \\
\hline BMI $\left(\mathrm{kg} / \mathrm{m}^{2}\right)$ & $25.31 \pm 3.18$ & $25.26 \pm 2.51$ & 0.05 & 0.04 & $0.96^{*}$ \\
\hline
\end{tabular}

$X \quad$ : Mean.

SD : Standard Deviation.

$p_{*}$-value : Probability value

MD : Mean Difference.

Table (2): Comparison of VAS, NDI and cervical ROM between pre and post-treatment in Group A and B.

\begin{tabular}{|c|c|c|c|c|c|c|}
\hline & \multicolumn{2}{|c|}{$\mathrm{X} \pm \mathrm{SD}$} & \multirow{2}{*}{ MD } & \multirow{2}{*}{$\begin{array}{c}\% \text { of } \\
\text { change }\end{array}$} & \multirow{2}{*}{$\begin{array}{c}t- \\
\text { value }\end{array}$} & \multirow{2}{*}{$\begin{array}{c}p- \\
\text { value }\end{array}$} \\
\hline & Pre-treatment & Post-treatment & & & & \\
\hline \multicolumn{7}{|l|}{ Group A: } \\
\hline VAS & $7.26 \pm 1.66$ & $2.33 \pm 1.11$ & 4.93 & 67.9 & 10.91 & $0.0001 * *$ \\
\hline NDI $(\%)$ & $62.94 \pm 10.33$ & $25.42 \pm 8.11$ & 37.52 & 59.61 & 15.85 & $0.0001 * *$ \\
\hline Flexion ROM (degrees) & $40 \pm 9.63$ & $56 \pm 8.9$ & -16 & 40 & -6.4 & $0.0001 * *$ \\
\hline Extension ROM (degrees) & $34.86 \pm 6.83$ & $59.6 \pm 9.86$ & -24.74 & 70.96 & -10.91 & $0.0001 * *$ \\
\hline Right rotation (degrees) & $36 \pm 8.7$ & $70.66 \pm 8.2$ & -34.66 & 96.27 & -11.93 & $0.0001 * *$ \\
\hline Left rotation (degrees) & $36.53 \pm 6.98$ & $72.33 \pm 9.23$ & -35.8 & 98 & -9.93 & $0.0001 * *$ \\
\hline Right side bend (degrees) & $29.66 \pm 9.72$ & $56.33 \pm 9.9$ & -26.67 & 89.91 & -11.74 & $0.0001 * *$ \\
\hline Left side bend (degrees) & $30.66 \pm 7.52$ & $58 \pm 9.78$ & -27.34 & 89.17 & -11.97 & $0.0001 * *$ \\
\hline \multicolumn{7}{|l|}{ Group B: } \\
\hline VAS & $7.06 \pm 0.88$ & $2.6 \pm 1.05$ & 4.46 & 63.17 & 14.57 & $0.0001 * *$ \\
\hline NDI $(\%)$ & $63.1 \pm 9.13$ & $32.5 \pm 4.91$ & 30.6 & 48.49 & 11.92 & $0.0001 * *$ \\
\hline Flexion ROM (degrees) & $42 \pm 4.92$ & $49.33 \pm 3.71$ & -7.33 & 17.45 & -6.2 & $0.0001 * *$ \\
\hline Extension ROM (degrees) & $35.33 \pm 4.8$ & $50.46 \pm 4.74$ & -15.13 & 42.82 & -11.34 & $0.0001 * *$ \\
\hline Right rotation (degrees) & $35 \pm 7.79$ & $51.66 \pm 7.23$ & -16.66 & 47.6 & -10 & $0.0001 * *$ \\
\hline Left rotation (degrees) & $34 \pm 7.6$ & $53.33 \pm 9.94$ & -19.33 & 56.85 & -10.64 & $0.0001 * *$ \\
\hline Right side bend (degrees) & $28 \pm 6.76$ & $44.26 \pm 8.2$ & -16.26 & 58.07 & -11.02 & $0.0001 * *$ \\
\hline Left side bend (degrees) & $29.33 \pm 5.93$ & $46.66 \pm 8.99$ & -17.33 & 59.08 & -8.17 & $0.0001 * *$ \\
\hline
\end{tabular}

X : Mean.

SD : Standard Deviation.

MD : Mean Difference

$p_{* *}$-value : Probability value

Significant. 
Table (3): Comparison of VAS, NDI and cervical ROM between Group A and B.

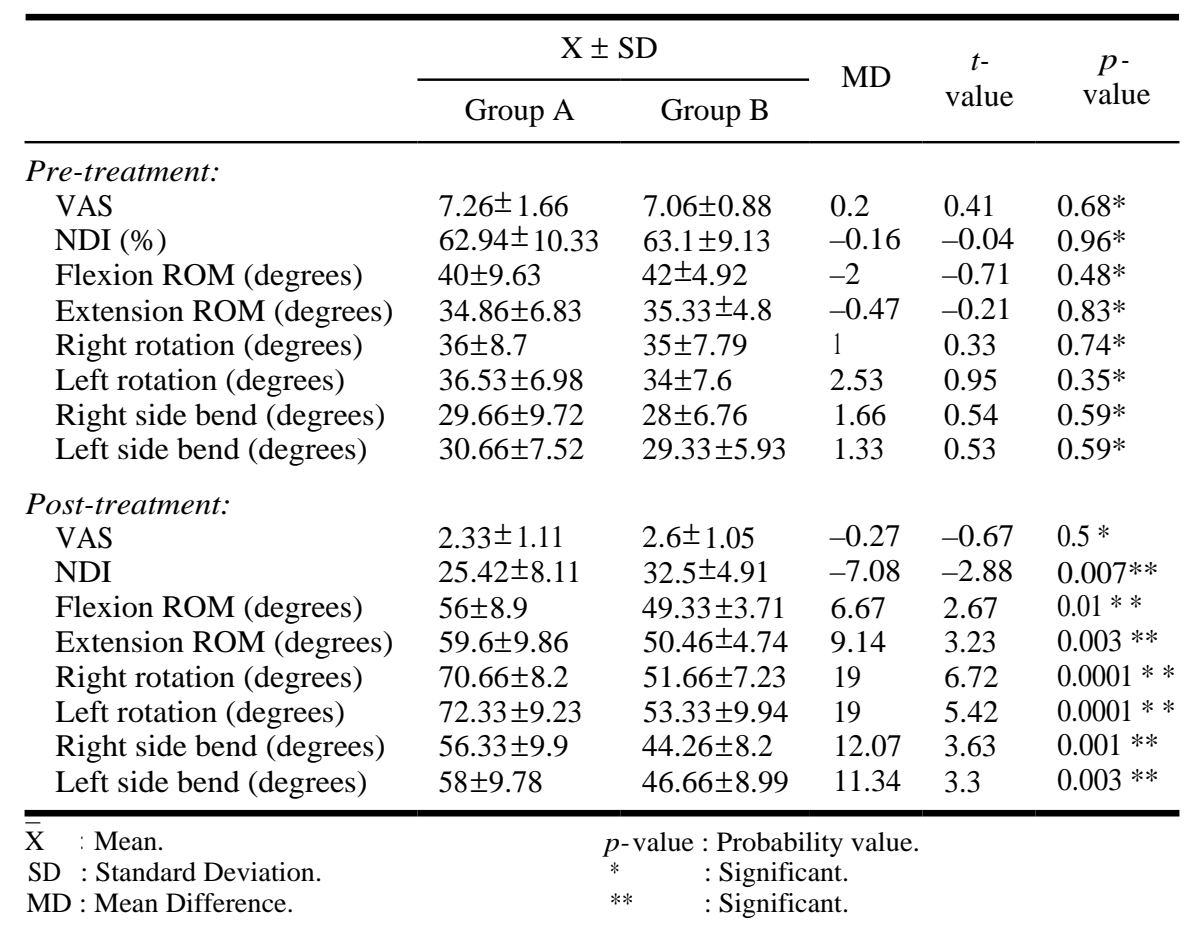

\section{Discussion}

Upper thoracic mobilization and cervical range of motion:

Results of this study indicated that after 4 weeks of upper thoracic mobilization in addition to routine physical therapy, the CROM significantly increased in comparison to the control group which received routine physical therapy only in terms of flexion, extension, left and right lateral flexion, and left and right rotation.

The findings of the present study have been supported by the work of McGregor et al., [13] who examined the effect of transvers mobilization for upper thoracic (T1-T6). They showed that after performing 8 minutes of the non-thrust mobilization technique to the upper thoracic spine, a significant increase in cervical extension and bilateral rotation. In the current study, the data was collected after 4 weeks (12 sessions) of physical therapy follow-up.

On the same line, study of lee et al., [16] investigated the effect of cervical and thoracic Maitland mobilization on chronic MNP. They concluded that improvement of active CROM in the treatment group who received upper thoracic and cervical mobilization and exercise in comparing with the control group who received only exercise. But this study didn't investigate the effect of upper thoracic mobilization only.
The present date is not in the same line with Suvarnnato et al., [6] who found that the CROM for the thoracic mobilization group significantly increased in some direction flexion and left rotation only by comparison with the control group. This study investigated only the short term effect of mobilization/manipulation at the T6-T7 vertebrae on CROM for patient with chronic MNP.

The present study suggests the upper thoracic mobilization increases CROM. This effect may be explained as the following, decreasing mechanical stress and increasing the distribution of joint forces in the cervical spine which achieved by restore the normal biomechanics and increasing thoracic mobility by the application of upper thoracic mobilization $[17,18]$. Finally, the improvement might be because Small amplitude oscillatory and distraction movements are used to stimulate the mechanoreceptors that may inhibit the transmission of nociceptive stimuli at the spinal cord or brain stem levels [19].

\section{Upper thoracic mobilization and neck function:}

The results of the current study indicate improvement the neck function of both group but when comparing both groups, the second group which received routine physical therapy and upper thoracic mobilization is better than the group which received only routine physical therapy. 
This result is in the same line of study of Ko et al., [15] which investigated the effects of the thoracic mobilization into cranio-cervical flexor exercise in patients with chronic neck pain. They reported that the larger improvement in neck function was in the group receiving thoracic mobilization and cranio-cervical flexor exercise.

The results of the present study agree with the work of Lee et al., [16], they concluded that the joint mobilization and therapeutic exercise for functional impairments caused by chronic MNP had a significant effect on several types of functional impairment more than exercises only. But their study investigated the effect of both cervical and upper thoracic mobilization at the same time.

The findings of the present study disagree with the work of Cleland et al., [11], the study compared between the short-term Effects of thrust versus nonthrust mobilization of upper thoracic in patients with MNP. The results suggested that thoracic spine manipulation results in significantly greater short-term reductions in disability than did thoracic nonthrust mobilization. But this study investigated the short term effect the date collected before and after 2 days from treatment session.

The improvement of neck function by applying upper thoracic mobilization may be explained by the following. Firstly, the upper thoracic mobilization can increase the dynamic stability of cervical spine of patient with mechanical neck pain [20] Secondly, the combination of upper thoracic spine mobilization and mobility exercise demonstrated better in standing posture for patient with forward head [21], good posture lead to improve neck function.

\section{The upper thoracic mobilization and neck pain:}

This study demonstrated significant improvement of resting pain level in both groups when comparing pre and post-treatment in each group. But there is no statistically significant difference in pain at post intervention among the control and the treatment group. The study is agreed with Suvarnnato et al., [6] but they investigate the short effect of only single mobilization of T6-T7 on MNP patient. The current study investigated the effect of upper 6 thoracic vertebras.

This finding differs from previous study for McGregor et al., [13] but they investigated the immediate effect of thoracic transverse mobilization for thoracic spine and they didn't determine acute or chronic cases. The current study investigated the effect of upper thoracic mobilization on MNP and follow-up after 12 sessions. The finding of this study also is disagreed the previous study of Ko et al., [15] who investigated the effect of thoracic mobilization on chronic MNP. Ko et al. study is low quality, its PEDRO scale is only 3.

\section{Conclusion:}

For patients with chronic MNP, when compared between the upper thoracic mobilization group with the routine physical therapy group, there was a statistically significant positive effect of upper thoracic mobilization on all CROM and neck function, although the was no a statistically significant effect on resting pain level. Based on our result, the upper thoracic mobilization has a positive effect on mechanical neck pain patient. Therefore, we recommend upper thoracic mobilization combined with routine physical therapy as a clinical intervention for neck pain patients

\section{References}

1- SILLEVIS R., CLELAND J., HELLMAN M. and BEEKHUIZEN K.: Immediate effects of a thoracic spine thrust manipulation on the autonomic nervous system: A randomized clinical trial. Journal of Manual \& Manipulative Therapy, 18 (4): 181-90, 2010.

2- PUENTEDURA E.J., LANDERS M.R., CLELAND J.A., MINTKEN P., HUIJBREGTS P. and FERNANDEZ-DeLAS-PEÑAS C.: Thoracic spine thrust manipulation versus cervical spine thrust manipulation in patients with acute neck pain: A randomized clinical trial. Journal of Orthopaedic \& Sports Physical Therapy, 41 (4): 208-20, 2011.

3- WRIGHT A., MAYER T.G. and GATCHEL R.J.: Outcomes of disabling cervical spine disorders in compensation injuries: A prospective comparison to tertiary rehabilitation response for chronic lumbar spinal disorders. Spine, 24 (2): 178-83, 1999.

4- KHOJA S.S., BROWDER D., DALIMAN D. and PIVA S.R.: Benefits of Thoracic Thrust Manipulation when Applied with a Multi-Modal Treatment Approach in Individuals with Mechanical Neck Pain: A Pilot Randomized Trial. Int. J. Phys. Med. Rehabil., 3: 306, 2015.

5- MAITLAND G.D., HENGEVELD E., BANKS $\mathrm{K}_{\mathrm{t}}$ and ENGLISH K.: Maitland's vertebral manipulation, edn. New York: Elsevier Butterworth-Heinemann, 320-1, 2005.

6- SUVARNNATO T., PUNTUMETAKUL R., KABER D., BOUCAUT R., BOONPHAKOB Y., ARAYAWICHANON P. and CHATCHAWAN U.: The effects of thoracic manipulation versus mobilization for chronic neck pain: A randomized controlled trial pilot study. Journal of Physical Therapy Science, 25 (7): 865-71, 2013.

7- RANEY N.H., PETERSEN E.J., SMITH T.A., et al.: Development of a clinical prediction rule to identify patients with neck pain likely to benefit from cervical traction and exercise. Eur. Spine. J., 18: 382-91, 2009. 
8- GRAHAM N., GROSS A.R., CARLESSO L.C., SANTAGUIDA P.L., MACDERMID J.C., WALTON D. and HO E.: Suppl 4: An ICON Overview on Physical Modalities for Neck Pain and Associated Disorders. The Open Orthopaedics Journal, 7: 440, 2013.

9- TSANG S.M., SZETO G.P. and LEE R.Y.: Normal kinematics of the neck: The interplay between the cervical and thoracic spines. Manual Therapy, 18 (5): 431-7, 2013.

10- VICENZINO B., COLLINS D. and WRIGHT A.: The initial effects of a cervical spine manipulative physiotherapy treatment on the pain and dysfunction of lateral epicondylalgia. Pain, 68 (1): 69-74, 1996.

11- CLELAND J.A., CHILDS J.D., FRITZ J.M., WHITMAN J.M. and EBERHART S.L.: Development of a clinical prediction rule for guiding treatment of a subgroup of patients with neck pain: Use of thoracic spine manipulation, exercise, and patient education. Physical Therapy, 87 (1): 9-23, 2007.

12- CROSS K.M., KUENZE C., GRINDSTAFF T. and HERTEL J.: Thoracic spine thrust manipulation improves pain, range of motion, and self-reported function in patients with mechanical neck pain: A systematic review. Journal of Orthopaedic \& Sports Physical Therapy, 41 (9): 633 42, 2011.

13-MCGREGOR C.I., BOYLES R., MURAHASHI L., SENA T. and YARNALL R.: The immediate effects of thoracic transverse mobilization in patients with the primary complaint of mechanical neck pain: A pilot study. Journal of Manual \& Manipulative Therapy, 22 (4): 191-8, 2014.

14- SUVARNNATO T., PUNTUMETHAKUL R., BOONPRAKOP Y. and PHADUNGKIT S.: Intratester reliability of three clinical methods of measuring active cervical range of motion in normal subjects: A preliminary study.
Journal of Medical Technology and Physical Therapy, 22 (2): 160-6, 2010.

15- CHO J., LEE E. and LEE S.: Upper thoracic spine mobilization and mobility exercise versus upper cervical spine mobilization and stabilization exercise in individuals with forward head posture: A randomized clinical trial. BMC Musculoskeletal Disorders, 18 (1): 525, 2017.

16- LEE K.S. and LEE J.H.: Effect of maitland mobilization in cervical and thoracic spine and therapeutic exercise on functional impairment in individuals with chronic neck pain. Journal of Physical Therapy Science, 29 (3): 5315, 2017.

17- EDMONDSTON S.J. and SINGER K.P.: Thoracic spine: Anatomical and biomechanical considerations for manual therapy. Manual Therapy, 2 (3): 132-43, 1997.

18- NorlANDER S. and NORDGREN B.: Clinical symptoms related to musculoskeletal neck-shoulder pain and mobility in the cervico-thoracic spine. Scandinavian Journal of Rehabilitation Medicine, 30 (4), 243-51, 1998.

19- BIALOSKY J.E., BISHOP M.D., PRICE D.D., ROBINSON M.E. and GEORGE S.Z.: The mechanisms of manual therapy in the treatment of musculoskeletal pain: A comprehensive model. Manual Therapy, 14 (5): 531-8, 2009.

20- KIM G., LEE S. and JEONG H.: Effects of upper thoracic joint mobilization on dynamic stability of patients with chronic neck pain. Journal of Physical Therapy Science, 23 (5): 753-6, 2011.

21- BAUTMANS I., VAN ARKEN J., VAN MACKELENBERG M. and METS T.: Rehabilitation using manual mobilization for thoracic kyphosis in elderly postmenopausal patients with osteoporosis. Journal of Rehabilitation Medicine, 42 (2): 129-35, 2010. 


\section{Appendix}

$+t+t+4$

\section{Neck Disability Index:}

The questionnaire been designed to give us information as to how your neck pain has affected your ability to manage in everyday. Please answer every section and mark in each section only the one box that applies to you. We realise you may consider that two or more statements in any one section relate to you, but please just mark the box that most closely describes your problem.

\section{Section 1: Pain Intensity:}

$\square$ I have no pain at the moment.

$\square$ The pain is very mild at the moment.

The pain is moderate at the moment.

The pain is fairly severe at the moment.

The pain is very severe at the moment.

$\square$ The pain is the worst imaginable at the moment.

Section 2: Personal care (washing, dressing, etc.):

$\square$ I can look after myself without causing extra pine.

$\square$ I can look after myself but it causes extra pine.

$\square$ It is painful to look after myself and I am slow and careful.

$\square$ I need some help but can manage most of my personal care.

$\square$ I need help every day in most aspcts of self care.

$\square$ I do not get dressed, I wash with difficulty and stay in bed.

\section{Section 3: Lifting:}

$\square$ I can lift heavy weights without extra pain.

$\square$ I can lift heavy weights but it gives extra pain.

$\square$ Pain prevents me lifting heavy weights off the floor, but I can manage if they are conveniently placed, for example on a table.

$\square$ Pain prevents me from lifting heavy weights but

$\square$ I can manage light to medium weights if they are conveniently positioned.

$\square$ I can only lift very light weights.

I cannot lift or carry anything.

\begin{tabular}{|l|}
\hline Office use only \\
Name \\
Date \\
\hline
\end{tabular}

Section 4: Reading:

$\square$ I can read as much as I want to with no pain in my neck.

$\square$ I can read as much as I want to with slight pain in my neck.

$\square$ I can read as much as I want with moderate pain in my neck.

$\square$ I can't read as much as I want because of moderate pain in my neck.

$\square$ I cannot read at all.

Section 5: Headaches:

$\square$ I have no headaches at all.

$\square$ I have slight headaches, which come infrequently.

$\square$ I have moderate headaches, which come infrequently. I have moderate headaches, which come frequently.

$\square$ I have severe headaches, which come frequently.

$\square$ I have headaches almost all the time.

\section{Section 6: Concentration:}

$\square$ I can concentrate fully when I want to with no difficulty.

$\square$ I can concentrate fully when I went to with slight difficulty.

$\square$ I have a fair degree of difficulty in concentrating when I want to

$\square$ I have a lot of difficulty in concentrating when I want to

$\square$ I have a great deal of difficulty in concentrating when I want to

$\square$ I cannot concentrate at all. 


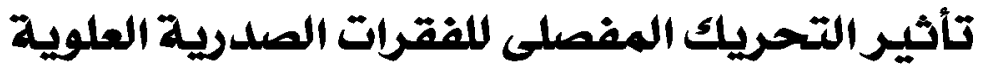

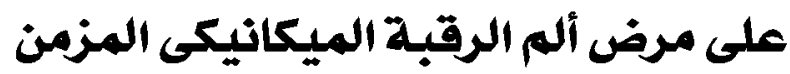

الخفلفية: يعتبر ألم الرقبة الميكانيكى من الأمراض الشائعة للجهاز العضلى الحركى فى الأشخاص البالغين والذى يؤثر سليياً على حياتهم اليومية وقدرتهم على العمل.

الغرض: توضيح تأثير التحريك المفصلى للفقرات الصدرية العلوية على مرض ألم الرقبة الميكانيكى المزمن.

الطريقة: شارك فى هذه الدراسة ـ ب مريض ومريضة وتراوحت أعمارهم بين العشرون والأريعين عام، تم تقسيمهم عشوائياً إلى مجموعتين.

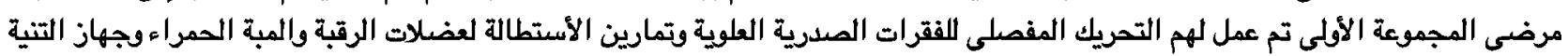

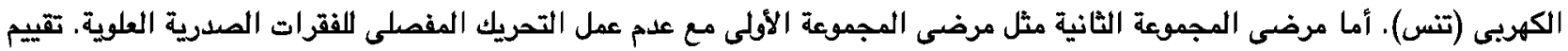

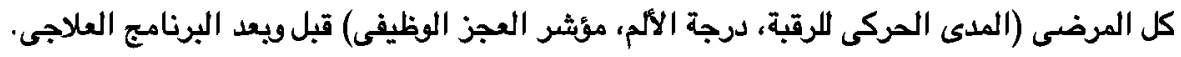

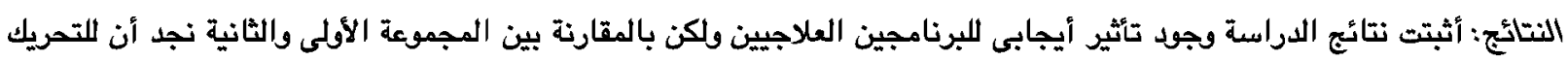

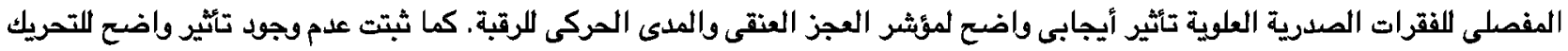

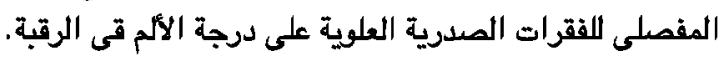

الأستتاجات: يعتبر التحريك المفصلى للفقرات الصدرية العلوية أحد الطرق لعلاج مرضى الألم العنقى الميكانيكى المزمن. 